First Peoples Child \& Family Review

An Interdisciplinary Journal Honouring the Voices, Perspectives, and Knowledges of First Peoples through Research, Critical Analyses, Stories, Standpoints and Media Reviews

\title{
Culturally Restorative Child Welfare Practice - A Special Emphasis on Cultural Attachment Theory
}

\section{Estelle Simard}

Volume 4, Number 2, 2009

URI: https://id.erudit.org/iderudit/1069329ar

DOI: https://doi.org/10.7202/1069329ar

See table of contents

Publisher(s)

First Nations Child and Family Caring Society of Canada

ISSN

1708-489X (print)

2293-6610 (digital)

Explore this journal

Cite this article

Simard, E. (2009). Culturally Restorative Child Welfare Practice - A Special

Emphasis on Cultural Attachment Theory. First Peoples Child \& Family Review, 4(2), 44-61. https://doi.org/10.7202/1069329ar

\section{Article abstract}

A research project was implemented through the use of qualitative secondary data analysis to describe a theory of culturally restorative child welfare practice with the application of cultural attachment theory. The research documented 20 years of service practice that promoted Anisinaabe cultural identity and cultural attachment strategies, by fostering the natural cultural resiliencies that exist within the Anishaabe nation. The research brings a suggested methodology to child welfare services for First Nation children the greater the application of cultural attachment strategies the greater the response to cultural restoration processes within a First Nation community.
This document is protected by copyright law. Use of the services of Erudit (including reproduction) is subject to its terms and conditions, which can be viewed online.

https://apropos.erudit.org/en/users/policy-on-use/ 


\title{
Initest Peoples Child \& samoily Review
}

An Interdisciplinary Journal Honoring the Voices, Perspectives and Knowledges of First Peoples through Research, Critical Analyses, Stories, Standpoints and Media Reviews

\section{Culturally Restorative Child Welfare Practice - A Special Emphasis on Cultural Attachment Theory}

\author{
Estelle Simard, MSWa
}

${ }^{a}$ Master of Social Work, University of Minnesota Duluth; Child Welfare Contractor (Fort Frances Ontario, Canada), British Columbia, Canada.

\section{Introduction}

Culturally restorative child welfare practice is one of the cornerstones for the rebuilding of a Nation. For centuries, governmental laws, regulations, policies, and practices have impacted First Nation people, families, and communities. These laws created latent consequences for First Nation people and have resulted in the creation of generations upon generations of social welfare casualties. Child welfare policies have been seen as intrusive and at times culturally inappropriate due to the continued difference between mainstream and Aboriginal worldviews on child welfare practices. A growing body of research suggests the need to create alternatives that support the recognition of culturally distinctive services practices (Rusk-Keltner, 1993; Brant, 1990), which promote better outcomes for First Nation children. Failure to change policies and regulations on First Nation child welfare practices leads to the over-representation of First Nation children in care across Canada (Blackstock, Trocmé, and Bennett, 2004). Often times, the engagement of family, extended family, and communities' falls short of the type of intervention needed to rebuild the family system. A consequence to the lack of culturally distinct practices are First Nation children becoming "split feathers", a term used to describe the deep loss effects of children displaced from their ancestral roots (Locust, 1998).



Questions or correspondence concerning this article may be estelle_simard@hotmail.com

\begin{abstract}
A research project was implemented through the use of qualitative secondary data analysis to describe a theory of culturally restorative child welfare practice with the application of cultural attachment theory. The research documented 20 years of service practice that promoted Anishinaabe cultural identity and cultural attachment strategies, by fostering the natural cultural resiliencies that exist within the Anishinaabe nation. The research brings a suggested methodology to child welfare services for First Nation children the greater the application of cultural attachment strategies the greater the response to cultural restoration processes within a First Nation community.
\end{abstract}

Although there have been some self-government gains with the creation of Native child welfare agencies, as with other provincial devolution models, "administrative control over child welfare services to Aboriginal authorities does not mean that the practice orientation will change, as it is still guided by the dominant protection paradigm" (Bellefeuille, Ricks, 2003). As an alternative to this paradigm, the research reviewed 10 historical videos which described the foundational practices of Weechi-it-te-win Family Services. The research, qualitative in nature, documented twenty years of service practices by looking at the theory of restorative child welfare which supports Anishinaabe children's cultural identity and cultural attachment. Weechi-it-te-win Family Services has harmonized and shaped a unique but anomalous service delivery that has protected Anishinaabe children and families in ten First Nation communities. The research project documented and discussed the unique practices of Weechi-it-te-win Family Services as they support the immediate and longitudinal benefits of child and families of the Rainy Lake Tribal Area.

Weechi-it-te-win Family Services, a transformative agency, has used cultural premises to set a standard of care that can be followed by mainstream social work 
practitioners when working with First Nation children. The cultural diversity and cultural integrity of Weechiit-te-win's model allows for the development of stand alone Native Child Welfare agencies or First Nation communities to champion their own children according to their own customs and traditions. The fluidity of Weechiit-te-win's model recognizes that cultural diversity is a necessary component in First Nation communities, as one size will not fit all. Further, the project documented child welfare paradigms and practices through the systematic review of the academic literature, contrasted with Weechiit-te-win Family Services practices.

The research project focused on cultural attachment theory as a mechanism to culturally restorative child welfare practices. Conversely the literature has shown attachment theory as an approach that has negatively impacted First Nation people whom are involved with child protection services. The immediacy of timelines in the promotion of healthy attachment of children with their caregivers is a significant cornerstone of this theory. The research project described how cultural attachment support and foster the wellbeing of our children, families, extended families, communities, and Nationhood. In the most humble of ways, the research project begins to lay a foundation to support the longitudinal benefits associated with this specific type of care and these specific types of services. It provided options and choices for practitioners to utilize in the creation of positive outcomes and alternatives for First Nation children and families involved with child welfare agencies. Further, the research project introduced standards of care into the literature further to the concepts of cultural identity, cultural attachment theory, and culturally restorative practices as best interest alternatives for First Nation children, families, and communities.

\section{Literature Review}

\section{History of First Nation People}

Looking at the history of First Nation people is one of the elements to culturally competent social work practice. Throughout the literature, there is a documentation of history in its most negative forms, with minimal research conducted on the inherent resiliencies which have existed for First Nations people. Weaver (2004) stated "knowledge, skills, and values/attitudes, are primary areas that have been identified consistently by scholars as the core of cultural competence with various populations [...] and culture, history, and contemporary realities of Native clients" ( p.30), as a beginning to this process with First Nation people. This means knowing the truth, appreciating, and understanding the history of First Nation people, and understanding how this history often brings about strong feelings towards cultural restoration in First Nation communities. Often time it is painful to look at the history of First Nation people across Canada. As it is often based in the realities of ostracism committed by church and state on vulnerable populations. This one sided paradigm of history does not capture the total history of First Nation people, as this recorded history does not typically include First Nation history and cultural norms from a First Nation perspective.

In our understanding of history we investigate the historical relationship between First Nation people and the "church and state" policies. But as First Nation people we are cautioned by our elders to not stay in the pain of history too long. They teach us to look at the internal strengths of our Nations, as it is the cultural laws that have guided how First Nation people govern themselves, their families, and their communities prior the beginning of colonization in 1492. In capturing the full spectrum of history, the positive and the negative, as scholars there exists the need to capture the essence of First Nation history and the resurgence of culture and teachings. It is the teachings, the language, and the cultural ceremonies that have been passed down from generation to generation, from elder to elder, from parent to child. Seeking this knowledge and applying it to current realities is an important aspect of culturally restorative child welfare practice.

\section{Historical Trauma}

William (2006) description of cultural competency through the lens of the critical theory paradigm looks at the outcomes of oppression through historical, political or economic constructs. In addition Weaver (1999) stated in culturally competent social work practice there exists "four important areas of knowledge: 1) diversity, 2) history, 3) culture, and 4) contemporary realities" (p. 220). As we begin to add to our body of knowledge in this area, specifically dissecting the historical implications involved in current realities for First Nation people, practitioners embark on understanding the root of the problems.

Irit Felsen's (1998) in his chapter Trans-generational Transmission of Effects of the Holocaust, spoke to the specific characteristics of survivors of the Jewish holocaust. He stated, "clinical reports suggest special characteristics of children of survivors and particular problems in the relationship between children and parents in survivor families, supporting the hypothesis of intergenerational transmission of Holocaust trauma" (p. 43). He specifically addressed Holocaust offspring as typically having "less differentiation from parents, less feelings of autonomy and independence, elevated anxiety, guilt, depressive experiences and more difficulty in regulating aggression" (Felsen, 1998, p. 57). Although Felsen's work addressed transmission of intergenerational 
trauma of Jewish holocaust survivors, other researchers have extended this philosophy to First Nation, American Indian, or Native American peoples throughout the United States of America to Canada (Morrissette, 1994; Yellow Horse Brave Heart, 2003; Duran, Duran, Yellow Horse Brave Heart, \& Yellow Horse- Davis, 1998; Duran \& Duran, 1995).

Morrissette (1994) discussed the holocaust of First Nation people, and specifically discussed the residential schools and how this genocidal experience continues to haunt First Nation people. Yellow Horse Brave Heart (2003) has a significant amount of research related to historical trauma, historical trauma response, and psychoeducational programs with the historical trauma in First Nation communities specifically the Lakota Nation. She defined historical trauma (HT) as "the cumulative emotional and psychological wounding over the lifespan and across generations, emanating from massive group trauma experiences" (Yellow Horse Brave Heart, 2003, p.7). She described historical trauma response (HTR) as "the constellation of features in reaction to this trauma, and that HT and HTR are critical concepts for native people, as increasing understanding of these phenomena, and their intergenerational transmission, should facilitate preventing or limiting their transfer to subsequent generations" (Yellow Horse Brave Heart, 2003, p.7). Duran et al., (1998) in their article Healing the American Indian Soul Wound, discussed the implications of First Nation traumatic history and the connection to the soul wound otherwise described by other researchers as "historical trauma, historical legacy, American Indian holocaust, intergenerational post-traumatic stress disorder" (Duran, et al.1998, p.341). The researchers go on to define elements of historical trauma as "features associated with depression, suicide ideation and behavior, guilt and concern about betraying the ancestors for being excluded from suffering as well as obligation to share in the ancestral pain, a sense of being obliged to take care of and being responsible for survivor parents, identification with parental suffering and a compulsion to compensate for the genocidal legacy, persecutory, and intrusive Holocaust as well as grandiose fantasies dreams, images and a perception the world is dangerous" (Duran et al., 1998, p.342). In addition to these characteristics, Duran et al., stated these emotional calamities are triggered by enduring acculturative stress. This acculturative stress is the result of history or historical legacy and latent consequences of laws and policies meant to help First Nation people. The link between history and contemporary issues for First Nation people is apparent. "The past 500 years have been devastating to our communities; the effects of this systematic genocide are currently being felt by our people. The effects of the genocide are quickly personalized and pathologized by our profession via the diagnosing and labeling tools designed for their purpose" (Duran et al., 1995). Utilizing culturally competent strategies to effectively deal with "grief resolution and healing from historical trauma response" (Duran, et al., 1998), has become an efficient clinical response. Further, psycho-educational programs on historical trauma, a process of disclosure within a group setting or in culture ceremonies, in addition to ceremonial grieving processes to promote community wellness and cohesiveness are all strategies used by Brave Heart (1998). The omission of historical trauma as a frame of reference for the social work profession is a gross injustice for First Nation people, as the unacknowledgement of history and its impact on current realities is by definition to continue culturally destructive practices.

\section{Canadian Profile}

A profile of First Nations people have been captured by the Assembly of First Nations (AFN, 2007). Today, there are a total of 633 First Nation communities across Canada with an estimated population of 756,700 First Nation members of these First Nation communities (AFN, 2007). The Assembly of First Nations stated that the most pressing problem that exists is the overall economic disparity between Canadians and First Nation communities. One instrument that shows this disparity is the human development index. "First Nation communities are ranked $76^{\text {th }}$ out of 174 Nations when using the United Nations Development Index 2001. This is compared to Canadian communities who ranked $8^{\text {th" }}($ AFN, 2007, p.3).

First Nation people of Canada continue to be challenged and faced with their children being culturally displaced, uprooted from their identity, and natural cultural resiliencies that exist within the First Nation continuum of care. An epidemic of Native children being placed in foster care systems throughout Canada is a growing concern for First Nation people. According to the Assembly of First Nation, "1 in 4 children live in poverty as compared to the National average 1 in 6" (p.2), furthermore, " as many as 27,000 First Nation children are currently under care" (p.2). The Canadian Incident Study on Reported Child Maltreatment (CIS98 ) is one current National study that has documented the over-representation of First Nation children in care across Canada (Trocmé et al., 2005). This research identified a total of " 76,000 children and youth placed in out of home care in Canada, 40 percent of those children are Aboriginal or children labeled "Indian" or "Native American", yet fewer that 5\% of the children in Canada are Aboriginal" (Trocmé et al., 2005, p.2). In some provinces 80 percent of the children in out of home placements are of First Nation descent (Trocmé, et al.). Blackstock, Trocmé, and Bennett (2004), stated 
"at every decision point in cases, Aboriginal children are overrepresented; investigations are more likely to be substantiated, cases are more likely to be kept open for ongoing services, and children are more likely to be placed in-out of home care" (p.1). The National research has indicated an "overrepresentation due to poverty, unstable housing, and alcohol abuse complicated by the experience of colonization" (Blackstock et al., 2004, p.14). In the light of this knowledge it is a vital indication of the need to re-evaluate mainstream child welfare practices with First Nation people.

\section{Child Welfare Laws and Implications for First Nation People}

First Nation people and social work advocates have a professional responsibility to change how laws, policies, and frameworks influence our people. There are numerous laws, policies, and regulations that have impacted First Nation people, so much so, First Nation communities are typically marginalized and collectively oppressed. There are two main destructive areas of policies, the first being the residential school policies and the second being child welfare policies and laws. Comeau and Santin (1995) stated, "in no other area did federal bureaucrats and professional social workers wreak so much havoc in so little time as in the field of child welfare" (p.141). In the best interest of children, judges, lawyers, and professional social workers dictated "the loss of an entire generation of children" (p. 141). Patrick Johnston, author of Native Children and the Child Welfare System, called this era the "sixties scoop" (p. 143). Comeau and Santin describe the amendments to the Indian Act in 1951, which gives provinical governments the jurisdiction to provide child welfare services on First Nation communities (p. 145), thereby washing their hands of their fudiciary responsibility to First Nation child welfare initiatives. Further, "by 1980, 4.6\% of all registered Indian children were in care across Canada, compared to less than $1 \%$ of all Canadian children" ( $\mathrm{p}$. 143). In addition to this statistic during the 1970-1980's, cross cultural placements were used as the primary modus operandi to adoption (p. 143). "In 1985, Edwin C. Kimelman, Associate Chief Judge of the Manitoba Family Court reported, "on Native adoptions and foster placements described the situation as the routine and systematize "cultural genocide" of Indian people" ( $p$. 145). The child welfare paradigm in Canada does not include cultural restorative practices as a standard of care for First Nation children.

\section{Implications of Attachment Theory}

Bowlby, the father of attachment theory, built on components of Freud's theory, hypothesizing an infant's need to explore, need for safety and security with the help of a significant caregiver (Waters and Cummings, 2000). Bowlby further hypothesized attachment as control systems or behavioral systems that are driven and shaped by evolutionary theory (Waters et al., 2000). Two major themes in Bowlby's work evolved a) secured base concept and b) working models (Waters et al., 2000). In their critical analysis of attachment theory, Waters and Cummings (2000) suggested a need to have criterion of application for review across cultures as it can erode the scientific consistency needed to maintain the theory. Further they stated, "Bowlby's emphasis on the early phase of attachment development has been a source of misunderstanding and missed opportunity - misunderstanding because it suggests that secure base behaviors emerges rather quickly and missed opportunities because it doesn't direct attention to the maintaining and shaping influence of caregiver behavior or developmental changes in secure base use beyond infancy, much less in the course of adult-adult relationships" (Waters, et al., 2000, p. 166). Waters and Cummings (2000), discussed the lifespan of a child into adulthood and point out the gap in between the life stages as being unknown; therefore, they suggest it is necessary to continue to develop "the effects of early experiences, the mechanism underlying stability and change, and the relevance of ordinary socialization processes in attachment development" (Waters, et al., 2000, p. 166).

In child welfare practice "the primary goals of child welfare and mental health professionals serving these maltreated children are to ensure their safety and protect them from further abuse, to help them heal from any physical or psychological effects of the maltreatment, and to provide opportunities for them to become healthier and well functioning children and adults" (Mennen, O'Keefe, 2005, p.577). Often permanency philosophies and timelines in child welfare have been guided by attachment theory. Timelines for securing change within the family systems do not allow for adequate time to change the individual, family and, at times, the communities. First Nation children and families often fall victims to the misapplication of attachment theory. A child welfare practitioners competing interest, noted by Mennen et al. (2005), is that "child welfare policy strives to use children's attachments as a guide to decisions about placements, but the demands of the system can interfere with this ideal. Increased caseloads, poorly trained workers, media attention, and political pressure often combine to lead to decisions that are not in children's best interest" (Mennen et al., 2005, p. 578). Often times attachment theory's link to suggested long term psychological issues, maladjusted members of society, or links to behavioral issues in relationship to societal safety 
have also been key factors in decisions of attachment and permanency planning in child welfare management. Berry, Barrowclough, and Wearden (2006) stated "attachment theory has the potential to provide a useful theoretical framework for conceptualizing the influence of social cognitive, interpersonal and affective factors on the development and course of psychosis, thus integrating and enhancing current psychological models. Insights derived from attachment theory have significant clinical implications, in terms of informing both psychological formulations and interventions with individuals with specific types of insecure attachment" (p. 472). Mennen et al. (2005) study had hypothesized the problematic behaviors are associated with a lack of immediate attachment to a significant caregiver. "Unfortunately the research on attachment behavior of children in foster care is limited and needs to be bolstered to provide a clearer understanding of how maltreatment, separation from parents, and placement in foster care influences attachment, and how foster children's attachment affect their long-term adjustment" (Mennen et al.,2005, p. 582).

It is important to note, there is a minimal amount of academic research on cultural attachment requirements related to either a generalist approach to service delivery or a more specific approach like working cultural attachment models specific to First Nation communities. The complete disregard to elements of cultural competency, historical implications and latent consequences of policies on First Nation people is evident in the literature. A defined culturally congruent child welfare service practice model is minimal if not nonexistent in the research. Currently there exists a deficiency on culturally specific research on First Nation children, and statistics continue to show a gross over-representation of First Nation children in the care across Canada.

\section{Cultural Competency}

Cultural competency in the field of human services has been the intention for many practitioners, but it is seldom realized. There are many reasons that have contributed to this dilemma. The incorporation of ethical standards and principles as it relates to culturally competent social work practice in addition to a growing body of literature emphasizing the importance of cultural competence, has not brought the direction and clarity that is needed to embrace such a criterion (Williams, 2006; Weaver, 2004). In addition to this predicament, the concept of cultural competence through the literature has not navigated one true path to the attainment of these standards and principles. The presence of ambiguity as it relates to defining cultural competency has left many practitioners with minimal tools to effectively and efficiently deal with clients in a manner that is conducive to the client's cultural orientation and framework
(Williams, 2006). As the literature has shown a growing trend to further cultural competence strategies, there is "little empirical work to provide professionals with specific principles or procedures for effective crosscultural work" (Weaver, 2004, p. 21), in particular with specific cultural groups such as the Anishinaabe Nation.

\section{Culture}

Culture has been defined in many different books, literature, journals, magazines, and dictionaries. Cross (2006), defined culture as "the integrated pattern of human behavior that includes thought, communication, action, beliefs, values, and institutions of a racial ethnic, religious or social group" (p.1). Day (2000) defined cultural epistemology as the "language and communication patterns, family, healing beliefs and practices, religion, art/dance/music, diet/food, recreation, clothing, history, social status, social group interactions, and values". Hogan (2007) stated that culture is learned, shared, and transmitted values, beliefs, norms and life ways of a group which are generally transmitted intergenerationally and influence one's thinking and action, and supplementary to this definition is the beliefs, the arts, the laws, morals, customs or values which make up the societal structure of a Nation (Wiley-Liss, 2005).

\section{Competency}

Williams (2006) stated, "culture defines the norms, symbols, and behaviors that aid us in making sense of the world. When there are gaps among service systems, practitioners, and clients, it contributes to misunderstandings and impasses that prevent effective social work intervention; seeking cultural competence is our response to that dilemma" (p. 210). Cultural competency suggests having some level, standard, or quality of understanding in working with another culture. This requires the act of acquiring knowledge and skills to meet the needs of the clients. Siegel, Davis-Chamber, Haugland, Bank, Aponte, and McCombs (2000), defined cultural competency as "the set of behaviors, attitudes, and skills, policies and procedures that come together in a system of agency or individuals to enable mental health care givers to work effectively and efficiently in cross/ multicultural situations" (p. 92). Cross (2006) provided a similar definition of cultural competence "a set of congruent behaviors, attitudes and policies that come together in a system, agency or professional and enable that system, agency or professional to work effectively in cross cultural situations" (p.1). Williams (2006) stated that "cultural competencies often are organized into categories for self awareness, attitudes, skills, and knowledge" (p. 210). Cultural competence requires the "systematic gathering of cultural information [...] on beliefs, practices, and characteristics of different ethno- 
cultural groups $[\ldots]$, generic social work skills $[\ldots]$, and competencies include self awareness [...], analysis of power structures [...], empowerment [...], critical thinking [...], and development of an effective working alliance" (Williams, 2006, p. 211).

\section{Organizational}

Cultural competence at an organizational level has been identified within the literature. In this analysis, there exists a range of subjective organization evaluations and quality assurance indicators. Cross (2006) identified a cultural competency continuum ranging from cultural proficiency to cultural destructiveness (Cross, 2006). This continuum included cultural destructiveness, cultural incapacity, cultural blindness, cultural pre-competence, basic competence, and advance cultural competence. Other research has shown performance measures and quality assurance mechanisms have been developed to evaluate the concept of culturally competent practices (Siegel, et al., 2000). Six domains were identified "needs assessment, information exchange, services, human resources, policies and procedures, and outcomes" (Siegel, et al., 2000, p. 95). In addition, the model evaluates each domain on three different organizational levels - administrative, provider network, and individual levels. Each domain and each level have outcome indicators to evaluate the effectiveness of culturally competent service delivery (Siegel, et al., 2000). All discussions on cultural competency at an organizational level are important, as it is the system that defines its policy, procedures, and direct service practice with client groupings.

Although definitions and descriptions of culture and cultural competence are extensive and at times illustrative they don't, by themselves, help practitioners attain competence. The literature has defined culture as the holistic make-up of a people, and the act of competent service practice is the acknowledgement and inclusion of culture into all levels of social practice with people - cultural competence. The manner in which we incorporate service standards and practice into accountable organizational frameworks is the threshold of cultural competence within any service organization.

\section{Weechi-it-te-win Family Services Mandate}

Weechi-it-te-win Family Services is a Native Child Welfare Agency in Fort Frances Ontario, Canada. Weechi-it-te-win Family Services (WFS) was established to create a change in the mainstream child welfare practice in Indian communities. The agency's services have evolved considerably over the last twenty years. The growth of the agency has been referred to as the iceberg phenomena (Simard, 1995), and is a symbol used to show the thaw of distrust for mainstream child welfare agencies. Weechi-it-te-win Family Services became an Aboriginal Children's Aid Society on September 2, 1987, under the Ontario Child and Family Services Act. As a Society, WFS has jurisdiction for services respecting the welfare of children and their families on within ten First Nation communities (Ferris, Simard, Simard, 2005).

Weechi-it-te-win Family Services began as a vision for a child and family services agency based on Anishinaabe customs and values. A Native model of child welfare called the Rainy Lake Community Care Program was developed based on goals adopted by the Council of Chiefs, namely: "To preserve Indian culture and identity among our people; To strengthen and maintain Indian families and communities; and To assure the growth, support and development of all our children within Indian families and communities" (Ferris et al., 2005 , p.5). There are six principles by which Community Care is consistent with community customs, standards and values. These principles are: "family focused; respectful; community oriented; community based; Native staffed; community directed" (Ferris et al., 2005, p.5). Since its inception, WFS has endeavored to provide child protection and family support services in ways that promote the preservation of Anishinaabe culture and identity, strengthen Anishinaabe families and communities and foster the growth and development of Anishinaabe children within Anishinaabe families and communities. It is believed that the spirit of cultural development for the agency is deeply rooted in the traditional laws and customs of the Anishinaabe Nation.
"The elders have advised and informed Weechi- it-te-win Family Services (WFS) that the agency has Cultural Rites as an Aboriginal Organization. The Cultural Rites arise from the fact that the Agency was born from Aboriginal aspirations and determination and as such was bestowed a Name and Ishoonun. In accordance to Aboriginal cultural thought, the Agency's Name came from the Atisookaanug as well as the emblem of the loon. The loon has provided numerous instructions to WFS on how the organization needs to operate and perform. Later, WFS was bestowed pipe(s), $\operatorname{flag}(s)$, a drum and medicines. Because of these sacred items, WFS has a duty to ensure that they are treated in a cultural manner that respects the original instructions from the Elders or ceremony that transferred these items to WFS. In additional to the Aboriginal cultural thought, the moment $W F S$ received its name it became more than a simple organization that provides services, it in fact became customarily personified in the eyes of the Atisookaanug. This means that WFS became a person, (much like the idea of a corporation under the Corporate Act), a living and breathing Aboriginal entity with a customary responsibility for family and cultural preservation." (Weechi-it- 
te-win Family Services, 2005, p. 2).

Instrumental to culturally competent strategies utilized within an agency system, it is imperative for every area of structures and services to integrate the cultural make-up or teachings of the community they serve. This is more than including culture as an afterthought; the culture is the foundation for agencies structure.

\section{Culturally Restorative Child Welfare Practices Models}

Limited information on culturally restorative child welfare practice has been found in the literature; however, many best practice models on First Nation child welfare practices are alive and well through out Canada and Abroad. The integration of cultural frameworks into service practice is not new, as First Nation child welfare or children's mental health agencies have been advocating for this type of practice for decades. As key First Nation stakeholders and First Nation service providers enter the world of academia, a forum for change in service delivery paradigms grows. It is essential to continue to address these in a manner that creates cultural understanding, values diversity, and supports culturally restorative child welfare practices. In the spirit of the transfer of knowledge, the researchers must "utilize the research initiatives of the world of academia, with the same vigor, but applied this research vigor to our cultural teachings of their Nationhood, and what a world of difference we would make for our children and our grandchildren to come" (Tibasonaqwat Kinew, 2006)

\section{Cultural Identity}

Cultural identity formation is an important aspect to cultural restoration processes. The literature advises careful reflection and critical analysis of the frame of reference in the presenting of the definitions of cultural identity for First Nation people (Oetting, Swaim, Chairella, 1998; Weaver, 2001; Peroff, 1997). Oetting et al (1998) discussed how identity changes over time, and the manner in which we define and evaluate cultural identification changes with time as well. Weaver and Yellow Horse Brave Heart (1999) stated "little is taught about how to assess where the client is in terms of cultural identity" (p. 20). Adding to the confusion about cultural identity is that cultural identity has been defined "from a non-native perspective. This raises questions about authenticity: who decides who is an indigenous person, Native or non-Native. The federal government has asserted a shaping force in indigenous identity by defining both Native nations and individuals" (Weaver, H., 2001, p. 245). Peroff (1997) in his article Indian Identity stated, "far more than with any other American racial or ethnic minority, American Indian identity or 'Indianness', is often expressed as a measurable or quantifiable entity" (p. 485). The example of this measurement given for the United States of America is the blood quantum. In Canada, this is also true for First Nation people as well and is defined as eligible for status, non-status, Métis, or Inuit. Weaver (2001) discussed the pitfalls of defining cultural identity and stated, "identity is always based on power and exclusion. Someone must be excluded from a particular identity in order for it to be meaningful ... and to search for the right criteria is both counterproductive and damaging" (p. 245). The literature goes on into several key areas: definitions of cultural identity from an indigenous perspective; a discussion on the themes of cultural traditions and revitalization; measurements of cultural identity (Weaver, 1996; Weaver, 2001; Weaver et al., 1999, Peroff, 1997; Oetting et al., 1998; Novins, Bechtold, Sack, Thompson, Carter, \& Manson, 1997); historical implications related to cultural identity; and the adoption of culturally restorative strategies into child welfare practice.

The concepts of cultural identity, cultural assessment, cultural attachment, cultural revitalization, and individual/ collective renewal are documented in the literature (Weaver, 1996; Weaver, 2001; Weaver, Yellow Horse Brave Heart, 1999, Peroff, 1997). Cultural identity is defined by Oetting et al., 1998, as the connection to a particular group due to "qualified classifications" or likeness that is "derived from an ongoing social learning process involving the person's interaction with the culture" further "cultural identification is related to involvement in cultural activities, to living as a member of and having stake in the culture, and to the presence of relevant cultural reinforcements that lead to perceived success in the culture" (Oetting et al., 1998, p. 132). Oetting et al. 1998, also discussed the importance of family, extended family, and community in the transmission of this cultural knowledge. Peroff (1997) discussed the concept of tribe or community identification and states "an Indian identity is the internal spark that sustains a living Indian community" (p. 491).

Weaver (2001) discussed culture identity in three domains: "self identification, community identification and external identification" (p. 240). She defined cultural identification as being based on "a common origin or shared characteristics with another person, group, or ideal leading to solidarity and allegiance" (Weaver, 2001, p. 241). She stated "identities do not exist before they are constructed ... and are shaped in part by recognition, absence of recognition or misrecognition by other" (Weaver, 2001, p. 241). Further identity is "multilayered, (and may include) sub-tribal identification like clan affiliations, tribes or regions, descent, or lineage" (Weaver, 2001, p. 242). Weaver discussed how "self perception is a key component of identity [...], identity 
is not static rather it progresses through developmental stages during which an individual has a changing sense of who he or she is perhaps leading to a rediscovered sense of being Native" (Weaver, 2001, p.243 ). She also suggests that as an individual age the cultural formations becomes stronger (Weaver, 2001).

There is a history of cultural identification assessments that begins with a mainstream worldview. Often times these models look negatively at other worldviews and compares levels of assimilation or acculturation into that mainstream worldview (Weaver, 1996). Weaver (1996) discussed these models of assessment: transitional models, alienation models, and multidimensional models of assessment on a continuum ranging on levels of cultural competence. The most current model of cultural identification assessment is the orthogonal cultural identification model (Oetting \& Beauvais, 1998; Weaver, 1996). Further to this type of assessment, the world of psychology has also implemented cultural assessment into their supportive documentation relevant to DSM-IV assessments (Novins et al., 1997). One of the mechanisms to achieve this goal was the development of an outline for cultural formation (Novins et al, 1997), the importance of the child's family system in the course of therapeutic treatment (Novins et al., 1997) and overall cultural identity formation.

Historical implications on cultural identity have also been described in the literature (Weaver, 1996; Weaver et al., 1999). The pattern of laws, policies, and regulations dictated on First Nation people had and continue to have dire impacts on First Nation people. Weaver et al. (1999) stated "when assessing Native clients, social workers should explore the relevance of historical trauma [...] discuss multi-generational trauma experienced by a client's family and nation [...] and recognize the trauma, then take the steps towards a recognizing and dealing with and healing that trauma is critical" (p. 29). Social workers must begin to utilize multi-generational geno-grams to support the exploration of collective trauma experience in Nationhood, in community, in extended family and with family. It is important to caution social workers of possible misconceptions, as historical trauma has often been used as a backdrop to permanency planning. This of course would be a gross error in cultural identity assessment as it would perpetuation a system that has existed for centuries.

The federal government's attempt to deal with the 'Indian problem' has led to a pattern of defining identity "based on the statistical extermination of indigenous people, thereby leading to an end to treaty and trust responsibilities" (Weaver, 2001, p. 247). As a result, cultural identity should encapsulate a holistic view based on self-perception, self identification, self in relations to family, community, nationhood, and others nations under different tribal affiliations. Further, identity development is a fluid system, evolving with time and nurturance. The beauty of cultural identity is eloquently captured in this quote, "the strength of the culture is so powerful and is embedded in the very nature of our existences, that even if all systematic oppression work and there was no ounce of culture left in us as a people and the only thing noticeable about us as different would be the color of our skin ... the culture is so strong that one day someone would dream ... and we as a nation would start over once again" (Kelly, 2007).

\section{Methods}

The research captured the knowledge and experience associated with the longitudinal development of an "Indian alternative" at Weechi-it-te-win Family Services. It was designed to address the question: What is culturally restorative child welfare practice? The researcher looked at ten, one to one and a half hours of qualitative video footage, which have existed within the agency as a part of curriculum development data archives. These data sets are a part of on-going training and curriculum development projects of Weechi-it-te-win and are part of the descriptive analysis of culturally restorative child welfare practice. The research was consistent with secondary data analysis that was guided by qualitative examination.

\section{Results}

Weechi-it-te-win is an agency that has developed a solid culturally competent social work practice. Weechiit-te-win's model of governance has pre-disposed a concept of collaboration with elders, tribal leaders and grassroots community members. As a result of oral tradition, they have been taught the concepts of culturally competent and congruent social work practice through an inductive learning style. The invaluable resources within the First Nations have been available to educate workers on cultural awareness/sensitivity for child welfare and children's mental health services whose main population is the ten First Nation communities of Weechi-it-tewin. As a result, of this collaborative effort, a cultural attachment theory has been re-vitalized, developed and fostered by the people of Weechi-it-te-win. This model has shown the importance of Cultural Restoration when working with First Nation populations based on ethical considerations, effective practice, evidence-based practice, and cultural skill development.

In review the data, it is clear to state the existence of the concept of Weechi-it-te-win (wiiji'ittiwin) before the organization became a corporate structure. The Anishinaabe concept of wiiji'ittiwin is difficult to translate, 
as most often the English language does not adequately equate to the true meaning of the word. Within the Anishinaabe language there exists systems, structures, meanings, teachings, legends, roles, responsibilities, and often time, ceremonies attached with that Anishinaabe translation. Many of these concepts of attachment within the Anishinaabe language is embedded with the understanding that the language is the heart of the people and carried in the very genetic structure of the Anishinaabe people. This review of the data and its presentation is based on the theoretical principles of establishing the rationale, revitalizing the teachings, and showing a mechanism to do so within the concept of wiiji'ittiwin helping and supporting children and families.

\section{Historical Context}

The historical context of Weechi-it-te-win begins with the understanding of family structures that existed before colonization, and is the main focus of much of the results within the research. Colonization, historical traumas and impacts, are latent consequences and present day realities that have touched Canada, Ontario, and the Northwestern part of Ontario in the Rainy River District. A consistent theme that has been documented is the ramifications of federal and provincial laws on child welfare practices in Canada that have seriously injured First Nation people in the Rainy River District. The First Nation population within the Rainy River district was an estimated $10 \%$ of the total population in the early 1960 s. As much as $80 \%$ of the children in care were First Nation children with the social services agencies of the time, clearly indicating the over-representation of First Nation children in care during that era. Some underlying factors that contributed to this fact were the absence of Anishinaabe child welfare and/ or the acknowledgment of the existence of Anishinaabe child welfare systems. Often times, the community standards were compared with mainstream practice. This was interlaced with the multigenerational pain of First Nation's peoples as a result of the despairing poverty, residential school trauma and 60's "scoop" losses. As a result, mainstream social welfare and child welfare agencies were mandated by the provincial government to deliver these services on behalf of the federal government. The problem that existed within the Rainy River district was a mainstream agency delivering services to First Nation people with the absences of cultural understanding or context. As a result, children were often removed from their homes, placed in non-Native homes, displaced from their communities, often times losing their identity as Anishinaabe thereby suffering a loss of attachment to the resiliency that exists within the Anishinaabe culture. As a result, Weechi-it-te-win was created as a response to the paradigm that existed during this point in time within the Rainy River District.
Throughout the years, the research has shown the absence in cultural context or cultural continuity, which had significant impacts on attachment to culture. Mass or generational removals of children in the First Nation communities began to erode the natural resiliencies that existed within the First Nation communities. The attitudes of mainstream workers were laced with an ethnocentric view that allowed the systematic oppression of a population. One of the interviewers stated the following, "workers did what they thought was best ... government did what they thought was best... but in practice they fell short of long term implications related to short sighted practice" (Lees, 1984). He went on to further say, "ignorant practice resulted in gross patterns of injustice for First Nation children, families, and communities" (Lees, 1984). The mainstream system focused narrowly on the child safety, removal, foster care placements, and adoption. This streamlined approach often did not engage the family, extended family or community. As a result of these minimal competencies in cross-cultural relationships there was a severance of family, extended family, and community. Often times, this left a wreckage of victimization and trauma due to the application of European standards and intervention on First Nation people.

The research indicated there wasn't a blanket acceptance, by First Nation people, of the child welfare paradigm in the early 1950 to 1985 , it was a system based on coercion. It is important to note, for those that were taken from their families and communities during this era, to understand the worldview of the time. It was an era of history based on extreme violence. Elders discussed the trauma being "so shocking to a people and a culture that it was often not talked about" (Tibasonaqwat Kinew, 2006). Another elder talked about the fight being taken out of them through years and years of government interventions and churches who tried to convert the tribal people. Community members, through their family systems, disclosed the history of Jesuits and Royal Canadian Mounted Police terrorizing people and cultures. As a result, there was often conversion to "mainstream ways" through trauma and threats. The research indicated laws and policies were put in place to disrupt the natural Anishinaabe systems. These included values, worldviews, standards and systems put in place for First Nation people only to eventually collide with each other, as often two worldviews do. It was in the early 1960's when advocates began to plead with social workers in the Rainy River district to begin to look at them as human beings; to deal with Natives with some compassion and to allow for child welfare governance to take place in the First Nation communities. It was always the intent of these advocates to re-establish tribal jurisdiction. Two key position governmental documents lead way to the development 
of the Weechi-it-te-win: “A Starving Man Doesn't Argue" (Unknown Author, 1979) and "To Preserve and Protect" (Unknown Author, 1983). Both government policy position papers discussed the ramifications of child welfare practice and the encouragement of First Nation child welfare jurisdiction in the First Nation communities.

A response to the paradigm of the time resulted in an assertion of tribal sovereignty across the Rainy River district. Examples ranged from First Nation road blocks to the guarding of tribal lands to ensure children would not be taken away by Children's Aid Society. Men like Moses Tom and Joseph Big George are credited with the community initiatives across the territory, the province and other provinces in Canada. Their commitment as tribal leaders to empower Anishinaabe child welfare systems was core to the development of the agency, but also core to the steadfast vision of "saving" First Nation children from the clutches of mainstream child welfare agencies and their systematic strategies to "take the Indian out of the child". The assertion of tribal control over child welfare is a consistent theme that has been voiced from the beginning and continues to be a driving theme across the decades. The political lead by PTO's across Ontario began to open discussions with the government to promote alternatives to child welfare. The value of commitment to these strategies has been passed on from generation to generation. This is seen through the political and community movement to promote the inherent strategies that exist within the Anishinaabe culture. For Weechi-it-te-win it is consistent in the tribal sovereignty development of the agency. This is clearly seen in the following timeline of policy development:

1970's the prevention programs in each of the 10 First Nations

1984 the planning committee designed to create the foundation of Weechi-it-te-win's and the community care program's vision, mission, goals, and objectives

1986 society status attained by Weechi-it-te-win

1990 cultural competency strategies were documented into bylaws, policies, and service practice

2000 the beginning of the devolution process for Weechi-it-te-win

2005 Weechi-it-te-win implemented Naaniigan Abiinooji as a best interest strategy for children of Weechi-it-te-win Family Services.

As an agency of National interest for the territorial Nation of Treaty \#3, Weechi-it-te-win is responsible to a restorative approach to child welfare. They do not condone or accept blindly the rapid child welfare changes under the Child and Family Service Act or its' amendments. Weechi-it-te-win's role is to be a resource to the communities in their attempt to rectify the damage done to their community as they rebuild their natural structures and to protect the communities from the continual distortion and exploitation of power exerted on First Nation people. Further, Weechi-it-te-win is true to the understanding "that the Native people have been a persecuted minority with the need to regain and resume their collective role in the raising of their children" (Lees, 1984).

The research themes have shown the need to change the policies always existed, but the government failed to acknowledge the cultural wisdom, often believing it had no place in modern day First Nation communities. It was important in the development of Weechi-it-te-win for it not to repeat the same pattern. As a result, there existed another important theme of a spiritual timeline in which cultural precepts, ceremonies, drums, and pipes were given to the agency, along with the responsibility and duty of care for these items on behalf of the children, families, and communities. These items are noted throughout the research as the heart of the agency's vision and spirit. With the cultural foundation and spiritual acknowledgement in place, Weechi-it-te-win began to embark on a spiritual journey of cultural restoration into child welfare practice. This practice has great importance as it has allowed for the collective responsibility of raising a child, with the instilling of values, traditions, roles and responsibilities of the First Nation community. Further it allowed for the opportunity to safeguard the child's inherent cultural identity and dignity related to the knowing of one's purpose and place within the cultural context of Anishinaabe mino-bimaatiziwin.

\section{Culturally Restorative Child Welfare Practice}

Cultural restoration is the rebuilding of a Nation of people based on the Anishinaabe teachings, language, principles and structures. It is based in the fierce love of Anishinaabe people for their children, and the creative thinking that has allowed for the creation and harmonization of strategies to empower Anishinaabe Naaniigan Abiinooji - Anishinaabe child welfare. It is the steadfast vision of the traditional governance structure and the First Nation advocates that has lead way to the creation of this system of care. Cultural restoration uses the concepts involved in the Naaniigan Abiinooji's Anishinaabe Natural Protective Network Principles. Some of these include customary care principles, best interest of the child principles, identity principles, developmental milestones principles, cultural placement principles, definitions of family principles, Anishinaabe rights of the child principles, cultural ceremony principles, and Anishinaabemowin - the language of the people to achieve this feat. All of these factors are the 
mechanism - cultural attachment theory - to achieve cultural restoration.

Throughout the research the project has suggested that the greater the application of cultural attachment strategies, the greater the response to cultural restoration processes within a First Nation community. This directly proportional proposition suggests an alternative strategy to governmental engagement with First Nation people, which are based on reinvestment in cultural attachment strategies in First Nation communities. Cultural presence in First Nation communities equates to increased trust and more access to services thereby bolstering higher caseloads - the iceberg phenomenon. The research has indicated a continual battle to justify the needs to alter programs and services for the betterment of First Nation communities. This continues to be a source of frustration described throughout the research.

Emerging Anishinaabe values in the Community Care Programs has stated, "children represent the future, and the future cannot be entrusted to the care of external government and public agencies. Reaffirming Anishinaabe identity requires control over community life, and preservation of Anishinaabe identity requires control over the care and protection of children" (Simard, 2006). The laws of the Anishinaabe are from the Creator thereby sacred. They have meaning, creating a bond and attachment to the expectation of the Creator for individuals, as Anishinaabe. These laws come with traditional customary obligations, known by the Anishinaabe. The research has also indicated that the Anishinaabe Nation was once a thriving Nation that took care of everyone, and continues to be a proud people and Nation. Collective responsibility and/or sacred responsibility were taken seriously. This is to be passed down from generation to generation via the oral teachings, birch barks scrolls, language, pictographs, rock paintings, and the petro-graphs found throughout Turtle Island (Jourdain, 2006).

The natural protective factors are the systematic structure, which has existed in within the Anishinaabe teachings for a millennium. The structure acknowledges the protective factors, the system needed to be in place, and the roles and the responsibilities of the people within the circles (Appendix 1). It shows the natural multifaceted and collective approach to raising a child. The approach acknowledges the importance of continuity for the child, the development of identity, the character, and the responsibility attached to child in their role within the Anishinaabe society. Within Weechi-it-te-win's training presentations, they have contrasted their approach with the mainstream approach as it relates to First Nation (FN) families, extended families, FN communities, and the Anishinaabe Nation.
As the previous documentation of history and the literature review have shown, the narrow approaches used by mainstream practices often falls short, thereby creating greater destruction to community restoration and child safety. A key piece noted by the research is "family preservation takes a secondary role within mainstream social work practice" (Simard, 2006). Further, the research has shown the child being ripped out of their inherent Anishinaabe family system and support structure. This of course is the crux of the problem, as it does not allow for continuity and restoration of Anishinaabe teachings and systems to take responsibility and accountability for raising their own.

The conceptual basis of the research is centered on the protective layers within the Anishinaabe society. The center of the protective layer is the child. The teachings related to the child begin with the Anishinaabe Rights of the Child Principle. The Anishinaabe Rights of the Child Principle was based in the teachings of the Anishinaabe; however, it was researched and documented by Jourdain in the early 1990's. It consists of the following:

"Spiritual name: Anishinaabe ishinikassowin

Clan: ododemun

Identity: anishinabewin

Language: anishinabemoowin

Cultural and healing ways: anishinabe miinigoosiwin

Good life: minobimatiziwin

Land: anishinabe akiing

Lifestye: anishinabechigewin

Education: kinamaatiwin

Protection: shawentassoowin and ganawentasoowin

Family: gutsiimug” (Jourdain, 2006)

The Anishinaabe rights of the child principle are consistent with an ethical assumption which links to concepts and laws in Naaniigan Abiinooji. It is meant to ensure a child has the spiritual foundation of inode'iziwin and the ability to balance their lives to achieve minobiimaatiziwin within their surroundings. This principle allows for the formation of identity within the context of Naaniigan Abiinooji, and is the best practice related to the raising of an Anishinaabe child. It is used as a mechanism to provide an opportunity for the child, family, extended family and community to collectively raise the child within the child's cultural context.

Identity is an important factor for Anishinaabe, although there are many concepts and meanings which define identity as shown in the literature review, Anishinaabe describe identity as a living, breathing force. 
It is a special link between a child and the Creator; it is not static and will not end. The concept is difficult to describe but the Anishinaabe word is Daatisookaanug - my spirit/my identity, and is similar to Atisookaanug which is of the spirit or the sum of the spirit, the all knowing and some might say, direct link to the Creator. The connection of identity to Anishinaabe is carried within the spirit, and it is the spirit that brings strength, love, ancestral knowledge, and a mode of being on Turtle Island. In Anishinaabe, we are of the spirit, and it is this connection of restoration which will rebuild a child, a family, a community and a Nation of people.

Further to the concepts of Anishinaabe Rights of the Child Principle, is the concept related to Anishinaabe Developmental Milestones Principles within practice. As in European principles on development, Anishinaabe have consistent teachings on Anishinaabe cultural milestones. If one researches the developmental milestones of a culture there are overarching similarities. The elders have discussed these concepts and some Anishinaabe have written and discussed this as a manner of introduction into Weechi-it-te-win's service practices. Jourdain (2006) has captured and discusses the elder's teachings on the Four Hills of Life, which are a teaching of the Anishinaabe society with an emphasis on the importance of cultural responsibilities related to the raising of a child. Jourdain (2006) discusses the traditional lifespan of the Anishinaabe and the unique healing component of achieving the "psycho-spiritual task" associated with each level. The levels are: "Abinodjiiwin - childhood; Oshkinigiwin - youth hood; Nitawigiwin - Adulthood; and lastly Kitisiwin - elderhood" (Jourdain, 2006). Jourdain also points out the tasks associated with each life stage. Abinodjiiwin is the time to develop the child identity, a time to develop trust and a time to make connections within the community. In Oshkinigiwin, it is a time of understanding the physical, emotional, mental and spiritual needs related to one's own being. It is a time in which one child would go to fast and receive his/her vision related to their own purpose. It is also a time in which the family would begin to prepare the young person to become a fully functioning adult within the Anishinaabe society. In Nitawigiwin, the young adult begins to learn about independence, procreation, parenthood and leadership. It is also a time in which the young person learns about collectiveness to the Anishinaabe people. It is a time in which the young person might also begin to learn about medicines and ceremonies, and maybe a time of initiation and convocations into a sacred lodge, which exists within Anishinaabe culture. There is a time, when the young adult takes on the role of advocate and protector of the Anishinaabe system. This is where the fierceness of love and protection come into play as an Anishinaabe often does not take this role lightly. The final stage is the Kitisiwin stage in which one is an elder. An elder is a very important part of this process as they are the keepers of the generational window. They are the keepers of the sacred medicines, the healing lodges, the ceremonies, customs, the language, and they are the teachers. Further the role of the elders are to promote the knowledge and wisdom related to the people, they are the disciplinarians, they are the promoter of Anishinaabe family systems, and they guide the lives of others in their sacred responsibilities of the Creator. Jourdain (2006) discusses the cultural ceremonies associated with the Hills of Life, such as "the welcoming ceremony; naming ceremony, clan identity; walking out ceremony; fasting; initiation ceremonies; traditional practices ceremonies; and sometimes the Creator gives traditional and ceremonial leadership rights to elders".

As in developmental tasks in European settings, cultural developmental milestones also have effects related to a lack of accomplishment. Within a cultural context there are many variables that can constitute cultural unrest and discord. Manifestations of this unrest are included as follows: "identity crisis; lack of supportive relationships; physical, emotional, mental and spiritual disturbances; there are manifestations of dysfunctions or dependencies; and in Elders, the person may be unable to share, support, love, communicate, be confident in leadership roles, and may possibly make decisions for Anishinaabe children and families in haste" (Jourdain, 2006). The possibilities that exist within the restoration of Anishinaabe systems far exceed the deficits related to restoring this type of practice with First Nation people. It is also important to note, although the research has show only one mode of developmental milestones for Anishinaabe, specifically Jourdain's teaching, the beauty of the Anishinaabe teachings are the diversity that exists within receiving the teachings on childhood development and rites of passage for the Anishinaabe child. When one family receives teaching on the cultural rites for a child, especially their own, there is much more meaning and attachment to the teaching received by the family, the extended family and the community.

The second layer of the natural protective network is the family. Within the research, the definition of family is much more than the nuclear family in mainstream systems. Anishinaabe family principles are structured on value based teaching within the concept of Naaniigan Abiinooji. The Anishinaabe family structure was a resilient mechanism in which the community all had sacred responsibility in the raising of a child and the mentoring of a fellow community member.

Jourdain (2006) has presented a "collective definition of family: 
Nuclear family: Immediate family, mom, dad, siblings

Extended family: Aunties and Uncles on Paternal or Maternal sides, cousins, second cousins, maternal family lineage and paternal family lineage

Community family: This is the membership of a First Nation community; Nation family: These are the members which exist within a treaty. For example Treaty \#3 is a nation and those members within this area are in fact family

Nationhood family: These are all the members of the Anishinaabe family, regardless of jurisdiction, provincial territories, or countries. It is all Anishinaabe

Clan family: There are significant teachings on clan and clan family which details the innate relationship to each other through our spiritual clan protector

Cultural family: The cultural family is linked to the ceremonial practices of the Anishinaabe. It is also the support within these circles of ceremonial activities" (Jourdain, 2006).

Building on this foundation on Anishinaabe family structures, Weechi-it-te-win has integrated a service placement model called the Cultural Placement. The principle is an ethical assumption, which is directly linked to the concepts and laws that exist in Naaniigan Abiinooji. Kishiqueb (2006) developed, presented, and discussed the implementation of this principle into practice in the early 1990 's. The principle was used to offer security for the child and to ensure the continuity of placement. It is used as a mechanism to provide an opportunity for the child, family, extended family and community to collectively raise the child within the child's cultural context. Reunifications with family systems were a prominent theme for the Anishinaabe children.

The placement principle is as follows: the community is aware of a child and family in need, typically the community will work with the family and attempt to provide services to mitigate risk of harm for the child. If intervention is needed, it is based on the resources that exist with the family system. "As a first resource the child is placed with immediate family, extended family, family within the community, extended family off reserve, family within neighboring communities, a Native family off reserve, then a non-Native family, or other facility off reserve" (Kishiqueb, 2006). This placement principle has proven to be successful, as Weechi-it-te-win has gone from placing children in $20 \%$ Anishinaabe homes to $85 \%$ Anishinaabe homes in 20 years of service practice. Further, in several of the communities, this principle has allowed for all children to be placed within their cultural context of family and community.

\section{Customary Care}

Another part of family within this protective shield is the concept of customary care. There are many facets to customary care principles, only some of which will be discussed within this paper. Customary care principles are a way of life established by the Anishinaabe people. It is the commitment to raising the children to ensure identity and rights of the child are adhered to, as they are a part of teaching vital life skills for each First Nation child. It is a community approach to making decisions on children and families by the community because they know the family and the families' needs. It is built with the premise that the worker lives within the community and has more opportunity to invest in the preventative and healing interventions of child welfare practices. It is based in love for the people as a main theme of a natural helper. One interviewee stated, "child welfare practice dictates social work education, but it is not necessary ... I'd be irresponsible to say formalized education is not relevant but I don't think it is essential to provide cultural competent services" (Lees, 1984). Another stated, "you need wisdom, kindness, respect ... this far exceeds the education anybody on earth can give you because we are all human beings, let's treat each other like human beings" (Tom, 1984). The underlying principle of customary care is the commitment to working in a respectful manner, speaking from the heart, with community as the voice that empowers a different approach than mainstream child welfare intervention.

The final layers of the natural protective network principle are the concepts of First Nation and Nationhood governance. The people within First Nation communities need to have the power to create the services to help and heal their own people. The services need to be based on decisions made by Chiefs and Councils whom consult actively with the elders and service providers of the community. This consultation allows for the development of fundamental rights to care for children through a community perspective, which is typically based on Anishinaabe systems and structures. As many chief and councils monitor through portfolio systems, the supervision of such structures has typically been empowered through Family Service Committees.

These committees have taken different forms, and can encompass different people; but the point of consultation and supervision is the main theme noted. Grandmothers on family services committees are a standard that has its roots in historical roles and structures. It is the people that make up the committees that supervise the team and direct the team in case planning and review. The team is accountable to the grandmothers of the family service 
committees. Within this system of care, the response to services is done up front. It is an interactive response that allows for life continuity for the child. The overall system is mentored, monitored and supported by Weechi-it-tewin Family Services.

As an agency Weechi-it-te-win has developed a sound practice within the concept of Naaniigan Abiinooji - inadequately translated to the best interest of the child. This concept encompasses many of cultural attachments necessary to the wellbeing of an Anishinaabe child. It is what we do as service providers to enhance the child's wellbeing in the areas of physical needs, emotional needs, mental needs, spiritual needs. It is also what we do as service providers to ensure the molding and supporting of the child's development in this area. Further it is how we bring in family and extended family or community members in their "traditional roles" as caregivers to the child. It is the collective accountability to the child and the family, and the concept of Naaniigan Abiinooji is the spiritual mechanism and/or traditional roles of helpers, we need to embrace to complete this task as service providers. Stakeholders within the video footage have differentiated between the mainstream concept of the best interest of the child and Naaniigan Abiinooji, and have found key differences. Both standards agree in the basic principles of rights for the child; however, Naaniigan Abiinooji requires more. In Weechi-it-te-win system, "Naaniigan Abiinooji requires safety, protection, basic needs, rights to culture, Anishinaabe children's rights, traditional teachings and education, traditional developmental milestones, immediate family, extended family, all significant relationships, clan traditional or adoptive community, land, language, Anishinaabe name, treaty rights, and ischooin niin (sacred items)" (Kishiqueb, 2006). As an agency it is our responsibility to ensure access to these standards of care for children in our care, thereby allowing the community to increase community wellness and wellbeing. This is one of the inherent roles of leadership in First Nation governance and Nationhood building.

Weechi-it-te-win's model has shown the sacredness of raising an Anishinaabe child and the some of the foundations based in cultural teaching of the Anishinaabe. Within the research, elders discussed the two main teachings related to responsibility and traditional ethics inherent in leadership. Firstly, is a teaching on Oozhegwaas - a spiritual being whom steals children when parents are engaged in other activities. Oozhegwas represents the possibilities of what happens when the natural protective factors that exist in First Nation communities are not working properly. It is a story about a grandmother's teaching on child care, a mother's reclaiming of her child, and a spirit being who steals a child. It is about the process the mother went through on her journey to reclaim her child, and is compared to the process of various First Nation communities in their attempt to restore cultural values in Anishinaabe child welfare practice.

The second responsibility related to leadership is the concept of non-interference. The concept of noninterference has been misunderstood by non-Native people for centuries. Often times you hear a person describing the concept and the misinterpretation of the principle leaves a person wondering if it is an appropriate response. The elders within the videos have described non-interference as understanding the sacred responsibility related to Creator's gift of free will. It is a teaching that is based in the scrutiny of life, of one's purpose, and is based in the highest of ethics and morals. It is based in a manner of thinking that is built on Naanabooz stories, creation stories, visions, and teachings of the Anishinaabe. It is a mechanism to process right and wrong, as well as to know one's place within all levels of being. Non-interference is based in the relational developmental or attachment to one's belief system - Anishinaabe, and it is the understanding of the great responsibility of choice/free will. Another way of stating it is, "the ability to choose to help or not to help, and to help all, not just Anishinaabe, but all of humanity. Ensuring we are all safe" (Henry, 2006).

Leadership in Anishinaabe is not an easy task according to the research. There are many stages of healing and commitment that exist within the Anishinaabe system's framework. But it is important to note the question throughout the research is what foundation do we want to work from? What standards or principles? And when they are defined, how can the communities work together to achieve restorative child welfare practice? This is the ethical dilemma associated with the concept of non-interference. It is a choice in leadership based on Anishinaabe cultural principles. Henry (2006) states, "never get complacent, Weechi-it-te-win; you are the helpers, the shakbewis, to the children, blaze a good landing spot for them, blaze a good road for them, so when they come there will be a good place for them amongst the Anishinaabe". This concept and theme is prevalent in all the leaders of the agency and the commitment to that vision is intact.

Cultural restoration, a principle often foreign to mainstream social work practice, can seem illusive. A child welfare system can adopt strategies to improve better outcomes for First Nation children. Much of the research has shown various cultural attachment strategies to support this venture. The creation of Weechi-it-tewin was a systematic approach to the administrative harmonization of the cultural concepts introduced in this research. The promotion of harmonization has allowed a 
systematic culturally competent organization to begin to devolve services to the First Nation community through the devolutions principles. This process allows for the spiritually educated task of implementing Abiinooji Innakonegewin (Anishinaabe Child Care Law), which is the enactment of the supreme Anishinaabe law on how to care for our children. These tasks require a commitment, an anchoring in the vision, and an assertion in child welfare sovereignty for the Anishinaabe Nation.

\section{Discussions}

An implication for practice is the concept of cultural diversity that exists on Mother Earth. The fluidity of Weechi-it-te-win's culturally restorative practice model with other Indigenous child welfare service agencies has many advantages and potential pitfalls through misapplication of the model. Cultural diversity is an essential component of this model, as it allows for the opportunity to investigate the true and Natural Laws that have been given to each Indigenous Nation. The cultural investment and opportunities this project provides are endless, as each Nation is rich in cultural knowledge. However, the absence of cultural lead by the Indigenous Nation into service practice could prove to be disrespectful to the central theme of culturally restorative child welfare practices, which is Nationhood empowerment.

The researcher believes it is important to take the cultural attachment theory to the next level in the world of academia and social work practice. For too long, First Nation people have been subject to a mechanism that does not work, and as a result our Nations have been continual victims to the shortsighted practice of policy makers, institutions, and agencies. The opportunities within cultural attachment into social work practice are an immense task. Literature, systematic study and research analysis is needed to support this theory. The principle of increasing cultural attachment strategies into practice should increase culturally restorative Nations. The Anishinaabe Nation is a proud Nation of people, and a theory to support that development is imperative.

\section{Conclusion}

The objective of the research was to attain and package the wisdom of Weechi-it-te-win with a level of competence and integrity that ensures the "inherent dignity and worth" of this organization. It was the intent to create, share, and mentor an environment in which other populations can achieve organizational change. The research captured cultural values and the possibilities inherent in cultural restorative child welfare practices. Anishinaabe worldviews and practices have had limited admittance to literature grounded in scientific journals and the research has opened new doors and opportunities for First Nation researchers.

Cultural attachment is found in the protective network principle and cultural restorative child welfare practice is the systematic embracing of culture to meet the cultural needs of the First Nation child. Cultural attachment is one tool for the rebuilding of a Nation of people. Cultural restorative child welfare practice is a conceptual framework based in the cultural teachings of a Nation; it is based on the ceremonial practices; it is found in the circle of protection; it is defined by the specific roles and responsibilities of a member within a Nation and their subsequent contribution to the development of the child's secure cultural attachment; it is found in the ceremonial and cultural developmental milestones with a Nation; and it is the full integration of these concepts into children's mental health and child welfare service delivery systems.

Weechi-it-te-win Family Services practice model has created a change in paradigm related to child welfare. The system initially was a response to mainstream child welfare, but its foundation was based in a concept that was rooted in the Anishinaabe teachings and ceremonies. The mandate was not to complete child welfare in the same manner as mainstream practice; the mandate was to find an alternative. The steadfast vision of the management has brought the agency to where it is today. Principles of change evolved into having a deeper understanding of the Anishinaabe culture and traditions, and this has been the greatest reward.

\section{Biography:}

Estelle Simard is from the Anishinaabe Nation. She is enrolled in the Doctor of Education in Educational Leadership/Curriculum and Instruction program with the University of Phoenix. Much of Estelle's experience is in the culturally competent management of children's mental health and child welfare services. She has direct supervisory and clinical services expertise with Aboriginal people and has specialized in family preservation strategies by incorporating cultural activities into service delivery and practice. In addition, she has presented at National and International forums on child welfare on "cultural attachment theory". This article contains excerpts from Ms. Simard's MSW research project with the University of Minnesota Duluth.

\section{References}

Assembly of First Nation. (2007). Royal Commission on Aboriginal People at 10 years: A Report Card. Retrieved from the world wide web: http://www.afn.ca/cmslip/ general/afn_rcap.pdf.

Assembly of First Nation. (2007). Fact Sheet - Top Misconceptions about Aboriginal Peoples. Retrieved from 
the world wide web: http://www.afn.ca/cmslib/general/ FS-TM-e.pdf.

Assembly of First Nation. (2007). Fact Sheet - First Nation Population. Retrieved from the world wide web: http:// www.afn.ca/article.asp?id=2918.

Assembly of First Nation. (2007). Residential School History. Retrieved from the world wide web: http://www.afn.ca/ residentialschools/history.html.

Attachment Reference. (2007). Retrieved from the world wide web: http://www.umn.edu/ ijka/cources/archive/attach.html.

Bellefeuille, G., \& Ricks, F. (2003). A Pathway to Restoration from Child Protection to Community Wellness. $1^{\text {st }}$ Annual Native Social Work Conference - Articulating Aboriginal Paradigms: Implications for Aboriginal Social Work Practice. January 23, 2003.

Berry K., Barrowclough C., \& Wearden A., (2006). A review of the role of attachment styles in psychosis: Unexplored issues and questions for further research. Clinical Psychology Review 27 (2007), p. 458-475.

Blackstock, C., Trocome N., \& Bennett M. (2004). Child Maltreatment Investigations Among Aboriginal and NonAboriginal Families in Canada. Violence Against Women $10(8), 1-16$

Brave Heart, M. (1998). The Return to the Sacred Path: Healing the Historical Trauma and Historical Unresolved Grief Response Among the Lakota Through a Psycho-educational Group Intervention. Smith Studies College in Social Work, 68 (3), 342.

Comeau, P., \& Santin, A. (1995). The First Canadians: A Profile of Canada's Native People Today (2 ${ }^{\text {nd }}$ ed.). Toronto, Ontario, CN: James Lorimer \& Company, Publishers.

Cross, T. (2006). Cultural Competence Continuum. Retrieved on January 20, 2007 from the worldwide web: http://www. nysccc.org/T-Rarts/CultCompCont.html.

Day, Priscilla (2005). Cultural Competence Conference. Fort Frances, Ontario Canada.

Duran, E., \& Duran, B., (1995). Native American Postcolonial Psychology. Albany New York: State University of New York Press.

Duran, E., Duran, B., Yellow Horse Brave Heart, M., \& Yellow Horse- Davis, S. (1998). The International Handbook of Multi-generational Legacies of Trauma ed. Yael Danieli. "Healing the American Indian Soul Wound." Plenum Press: New York, 1998.

Ellison Williams, E. and Ellison, F. (1996). Culturally Informed Social Work Practice with American Indian Clients: Guidelines for Non-Indian Social Workers. Social Work, 41 (2), $147-150$

Felsen, I. (1998). The International Handbook of Multigenerational Legacies of Trauma ed. Yael Danieli. "Trans generational Transmission of Effects of the Holocaust." Plenum Press: New York, 1998.

Ferris, P., Simard, E., Simard, G., \& Ramdat, J. (2005). Promising Practices in First Nation Child Welfare
Management and Governance: Weechi-it-te-win Family Services: Utilizing a Decentralized Model in the Provision of Bi-cultural Services. Retrieved from the World Wide Web: http:www.fncfcs.com/docs/WFSPromisingPractices. pdf.

Gehue, David (2007). Traditional Teaching Lecture. Fort Frances, Ontario, CN.

Henderson, J. (1984). Weechi-it-te-win Family Services Interview. Fort Frances, Ontario.

Henry, L. (2006). Traditional Teaching Lecture and Presentation. Fort Frances, Ontario.

Hogan, M. (2007). The Four Skills of Cultural Diversity Competence: A process for understanding and practice. Belmont, CA: Thomson Higher Education.

Jourdain, L. (2003). Cultural Competence in Child Welfare Lecture and Presentation. Fort Frances, Ontario.

Jourdain, Larry (2006). Anishinaabe Child Welfare Lecture and Presentation. Fort Frances, Ontario.

Kelly, Fred (2007). Traditional Teaching Lecture and Presentation. Fort Frances, Ontario, CN.

Kishiqueb, Kathy (2006). Naaniigan Abinooji Presentation. Fort Frances, Ontario, CN.

Lees, Jim (1984). Weechi-it-te-win Family Services Interview. Fort Frances, Ontario.

Locust, Carol (2000). Split feathers - Adult American Indians Who Were Placed in Non-Indian Families As Children. OACAS journal 44 (3), 11-16.

Mennen F.E., \& O'Keefe M.O., (2005). Informed decisions in child welfare: The use of attachment theory. Children and Youth Services Review 27, 577-593.

Morrissette, Patrick, J., (1994). The Holocaust of First Nation People: Residual Effects on Parenting and Treatment Implications. Contemporary Family Therapy, 16 (5).

Novins D.K., Bechtold D.W., Sack W.H., Thompson J., Carter D.R., \& Manson S.M. (1997). The DSM IV outline for cultural formulations: A critical demonstration with American Indian children. Journal of the American Academy of Child and Adolescent Psychiatry, 36 (9), 1244 (8).

Oetting, E.R., Swaim, R.C., \& Chiarella, M.C. (1998). Factors structure and invariance of the orthogonal cultural identification scale among American Indian and Mexican American youth. Hispanic Journal of Behavioral Sciences, 20, (2), 131 (24).

Peroff, N.C., (1997). Indian Identity. The Social Science Journal, 34 (4), 485 (10).

Rusk-Keltner, B. (1993). Native American Children and Adolescents: Cultural Distinctiveness and Mental Health Needs. Journal of Child and Adolescent Psychiatric and Mental Health Nursing, 6 (4), 18-23.

Simard, S. G., (1995). Historical Lecture on Weechi-it-te-win Family Services. Fort Frances, Ontario. Canada. 


\section{Culturally Restorative Child Welfare Practices}

Simard, S.G., (2006). History of Weechi-it-te-win Family Services Lecture. Fort Frances, Ontario.

Simard, E (2006). Rethinking Attachment Theory: Culturally Restorative Child Welfare Practice Lecture. Fort Frances, Ontario.

Siegel, C., Davis-Chambers, E., Haugland, G., Bank, R., Aponte, C., \& McCombs, H. (2000). Performance Measures of Cultural Competency in Mental Health Organizations. Administration and Policy in Mental Health, 28 (2), 91-106.

Tibasonaqwat Kinew, (2006). Traditional Teachings Lecture. Fort Frances, Ontario, CN.

Tom, M. (1984). Weechi-it-te-win Family Services Interview. Fort Frances, Ontario.

Trocme, N., Knoke, D., \& Blackstock, C. (2004). Pathways to the Overrepresentation of Aboriginal Children in Canada's Child Welfare System. Social Service Review 78 (4). Retrieved from the world wide web: http://scholar.google. $\underline{\mathrm{ca} / \mathrm{scholar} \text { ?h } 1=\text { en \& } 1 \mathrm{r}=\& o \mathrm{i}=\mathrm{qs} \& \mathrm{q}=\text { nicp }+ \text { trocme }+ \text { author }}$ :n-trocme.

Water E., \& Cummings E.M., (2000). A Secure Base from Which to Explore Close Relationships. Child Development $71(1), 164-172$

Weaver, N. Hilary (1996). Social Work with American Indian youth using the orthogonal model of cultural identification. Families in Society, 77 (2), 99-109.

Weaver N. Hilary, \& Yellow Horse Brave Heart, M. (1999). Examining Two Facets of American Indian Identity: Exposure to Other Cultures and the Influence of Historical Trauma. Journal of Human Behavior and the Social Environment. 2 (1/2), 19-33.
Weaver, N. Hilary (1999). Indigenous People and the Social Work Profession: Defining Culturally Competent Services. Social Work, 44 (3), 217- 225.

Weaver, Hilary (2000). Culture and Professional Education: The Experience of Native American Social Workers. Journal of Social Work Education, 2000 (36), 415.

Weaver N., Hilary (2001). Indigenous Identity: what is it and who really has it? American Indian Quarterly, 25 (2), 240-255.

Weaver N., Hilary (2004). The Elements of Cultural Competence: Applications with Native American Clients. Journal of Ethnic \& Cultural Diversity in Social Work, 13 (1), 19-35.

Wipikedia (2008). Human Development Index. Retrieved from the world wide web: http://en.wikipedia.org/wiki/ Human_Development_Index.

Weechi-it-te-win Family Services, 2005. By-Law number 1: A $B y$-Law relating generally to the transaction of the affairs of Weechi-it-te-win Family Service, Inc

Wiley-Liss. (2005). Media Review: Moving Beyond Culture. American Journal of Primatology, 66, 293-295.

Williams C., C., (2006). The Epistemology of Cultural Competence. Families in Society, 87 (2), 209-222.

Yellow Horse Brave Heart, M. (2003). The Historical Trauma Response Among Natives and its Relationship with Substance Abuse: A Lakota Illustration. Journal of Psychoactive Drugs, 35 (1), 7. 


\section{Appendix One}

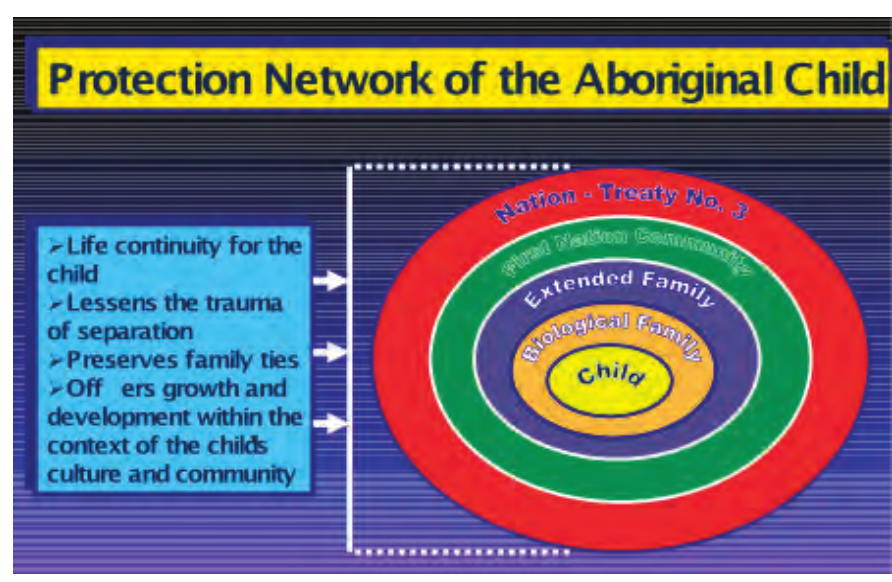

Protection Network of the Aboriginal

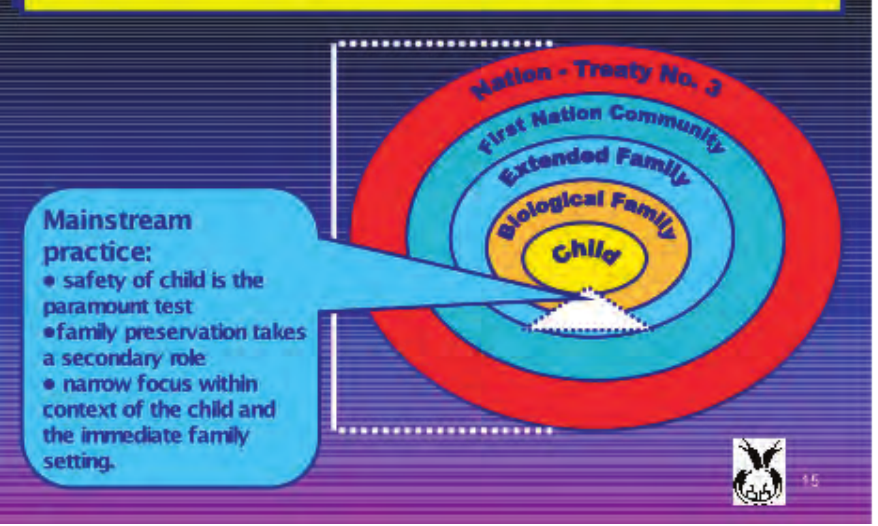

Protection Network of the Aborigin

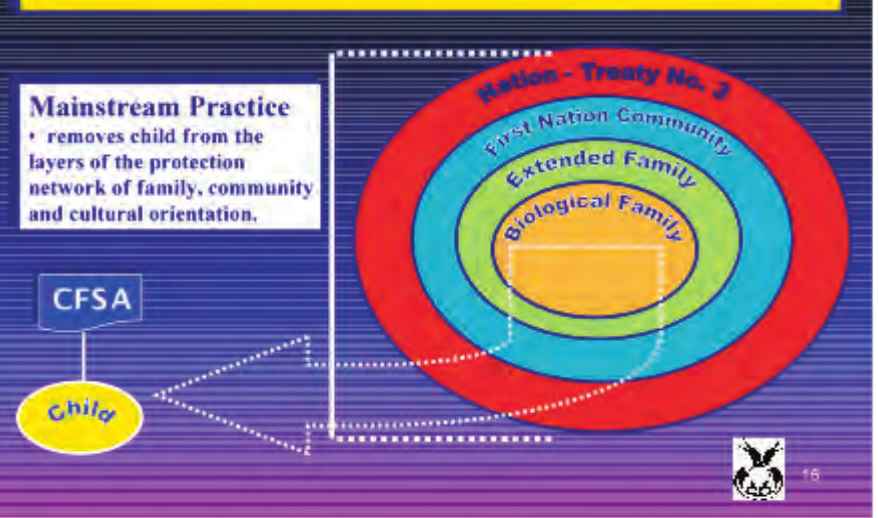

() Estelle Simard

\section{Natural Protective Network Principle:}

The natural protective factors are the systematic structure which has existed in within the Anishinaabe teachings for a millennium. The structure is a principle of the Anishinaabe Nation and acknowledges the protective factors, the system needed to be in place, and the roles and the responsibilities of the people within the circles. It shows the natural multi-faceted and collective approach to raising a child. The approach acknowledges the importance of continuity for the child, the development of identity, the character, and the responsibility attached to child in their role within the Anishinaabe society.

S. George Simard, 2008

\section{$\underline{\text { Part } 2 \text { of } 3}$}

Within Weechi-it-te-win's presentations they have contrasted their approach with the mainstream approach as it relates to impacts for First Nation families, extended families, FN communities, and even the Anishinaabe Nation. The narrow approaches used by mainstream practices often falls short thereby creating greater destruction to community restoration and child safety. A key piece noted by the research is "family preservation takes a secondary role within mainstream social work practice" (G. Simard, 2006).

S. George Simard, 2008

\section{Part 3 of 3}

Further the research has shown the child being ripped out of their inherent Anishinaabe family system and support structure. This of course is the crux of the problem as it does not allow for continuity and restoration of Anishinaabe teachings and systems to take responsibility and accountability for raising their own.

S. George Simard, 2008 